\title{
Significance of IL-6 Deficiency in Recognition Memory in Young Adult and Aged Mice
}

\author{
Izabela Bialuk ${ }^{1} \odot \cdot$ Piotr Jakubów $^{1} \cdot$ Maria Małgorzata Winnicka ${ }^{1}$
}

Received: 21 September 2018 / Accepted: 13 May 2019 / Published online: 25 May 2019

(c) The Author(s) 2019

\begin{abstract}
Chronic peripheral elevation of interleukin 6 (IL-6) in humans is associated with cognitive deficits. 4- and 24-month-old IL6-deficient C57BL/6J (IL-6KO) and reference wild-type (WT) mice were tested in an object recognition test. Discrimination ratios and recognition indexes were significantly lower in 4-month-old IL-6KO and in 24-month-old WT mice vs 4-month-old WT animals. Their discrimination ratios had negative values and recognition indexes were below $50 \%$ indicating inability to differentiate the novel from the familiar object after 1-hour delay. In 24-month-old IL-6KO mice recognition index reached $53.17 \%$ indicating that their recognition memory was not worsened with age in comparison with younger IL-6-deficient animals. Results of holeboard and elevated plus maze indicated that this effect was memory specific. Inborn IL-6 deficiency attenuated recognition memory in 4-month-old mice and did not altered recognition memory in aged animals. IL-6 signalling may constitute a target for development of the protection against memory disturbances connected with IL-6 overexpression.
\end{abstract}

Keywords IL-6 deficiency · Object recognition memory $\cdot$ Holeboard $\cdot$ Elevated plus maze $\cdot$ Mice

\section{Introduction}

Interleukin 6 (IL-6) is a multifunctional cytokine, with context-dependent pro- and anti-inflammatory properties (Hunter and Jones 2015; Trapero and Cauli 2014; Yirmiya and Goshen 2011). Clinical observations on humans have demonstrated an age-associated chronic peripheral increase in IL-6 level inversely correlated with cognitive decline (Marsland et al. 2006; Mooijaart et al. 2013; Simpson et al. 2013; Weaver et al. 2002; Wright et al. 2006). Moreover, the detrimental role of IL-6 in age-related memory disturbances was demonstrated in senescence-accelerated mice (Tha et al. 2000) implying that IL-6 is involved in the impairment of

Handling Editor: Sonoko Ogawa

Electronic supplementary material The online version of this article (https://doi.org/10.1007/s10519-019-09959-6) contains supplementary material, which is available to authorized users.

Izabela Bialuk

izabela.bialuk@umb.edu.pl

1 Department of General and Experimental Pathology, Medical University of Białystok, Mickiewicza 2c, 15-222 Białystok, Poland learning and memory processes in normal aging (Godbout and Johnson 2004; Weaver et al. 2002; Wright et al. 2006).

Despite the facts pointing to the important role of IL-6 in neuroinflammatory and neurodegenerative diseases little is known about biological actions of this cytokine under physiological conditions and how they affect cognition (McAfoose and Baune 2009). It could be expected that because of a deleterious effect of increased IL-6 level on cognitive functions, its deficiency would be beneficial for these processes. However, in our previous study, 12-14-week-old, IL-6-deficient mice showed impaired memory processes in an object recognition test (Hryniewicz et al. 2007). This unexpected result concerning recognition memory was also described in a novel object recognition test performed on 6-month-old IL-6-deficient mice (Baier et al. 2009). Moreover, results of our study performed in Morris water maze (Bialuk et al. 2018), evaluating spatial memory, showed significant attenuation of learning ability in IL-6-deficient mice that was more pronounced in younger than in aged animals. However, it was difficult to answer the question whether inborn IL-6 deficiency slows down age-related memory decline because the swimming performance in IL-6 knock-out mice was significantly slower than in control, producing endogenous IL-6, animals. Therefore, in the current study we compared cognitive processes in 4- and 24-month-old IL-6-deficient 
and age-matched control mice in an object recognition test, less affected by locomotor activity alterations, and closely related to conditions under which human recognition memory is evaluated (Ennaceur and Delacour 1988).

\section{Materials and methods}

\section{Animals}

Naïve, male young adult (4-month-old) and aged (24-monthold) IL-6-deficient mice C57BL/6J $\mathrm{J}^{\mathrm{IL}-6-/-\mathrm{TMKopf}}$ (IL-6KO) and reference age-matched wild-type (WT) animals (C57BL/6J) were used. Each group consisted of 10 mice. Animals, obtained from the Centre for Experimental Medicine of the Medical University of Białystok, originally purchased from the Jackson Laboratory (USA), were used in experiments performed after at least 14 days of acclimatization to the laboratory conditions. The mice were maintained in a temperature-controlled conditions $\left(22 \pm 1{ }^{\circ} \mathrm{C}\right)$ with a $12 \mathrm{~h}$ light-dark cycles beginning at $7 \mathrm{am}$ and were housed in polycarbonate cages, five animals per cage, with water and commercial food available ad libitum. Before experiments mice were handled for cage cleaning and weighing. All experiments were approved by the Local Animal Ethics Committee in Bialystok, Poland and were performed in compliance with the European Communities Council Directive 2010/63/EU.

\section{Experimental design}

Behavioral tests were carried out between 8.30 am and $12.30 \mathrm{pm}$ in an air-conditioned, sound-isolated room with regulated light intensity. During one experiment five animals of both genotypes were submitted to three behavioral tests. On day 1 a holeboard test, followed by an elevated plus maze test were carried out. Subsequently, on the same day a habituation session in an object recognition apparatus was conducted. On day 2 an object recognition test was performed. Apparatuses were cleaned with 70\% ethanol after each group of animals. An investigator, who was not familiar with the animal's genotype and age, carried out experiments. Subsequently, an independent researcher who was given an evaluation form watched recorded experiments and assessed animal's behaviour.

\section{Behavioral tests}

\section{Holeboard test}

The experiments were performed according to the modified method previously described (File and Wardill 1975). The apparatus was a grey wooden box with a square floor of $53.5 \mathrm{~cm} \times 53.5 \mathrm{~cm}$ divided into 25 equal parts and surrounded by a $42 \mathrm{~cm}$ high wall. Four holes in the floor $(2.5 \mathrm{~cm}$ in diameter) were designed as objects of possible interest to the animals. The apparatus was placed on the floor and lit with the intensity of $30 \mathrm{~lx}$. The animal was placed in the center of the holeboard box and its behavior was observed for $5 \mathrm{~min}$. Locomotor activity (ambulation, horizontal activity) was measured as the number of squares crossed with all four limbs. Exploratory activity (vertical activity) was measured as the number of rearing events (rises of an animal on its rear limbs, either with forelegs leaning against the wall or away from the wall), and the number of head-dips (when a mouse lowered its head into a hole, so the eyes disappeared beneath the plane of the floor). During assessment of ambulation, horizontal and vertical activities were recorded. The number of crossed squares adjacent and not adjacent to the apparatus walls was used to measure peripheral and central activity, respectively. Moreover, latency time to leave the central area was also recorded to measure anxiety level.

\section{Elevated plus maze}

The procedure was performed immediately after the holeboard test, according to the modified method previously described (Pellow et al. 1985). The apparatus, made of the same material as the holeboard box, was raised $80 \mathrm{~cm}$ above the floor with constant illumination of $75 \mathrm{~lx}$ at its level. The elevated plus maze consisted of four arms: two open, $30 \mathrm{~cm}$ $\times 7 \mathrm{~cm}$, and two closed arms $31 \mathrm{~cm} \times 7 \mathrm{~cm} \times 35 \mathrm{~cm}$, with an open roof. The arms were arranged in such a manner that the two open arms were opposite to each other and connected with the central area $7 \mathrm{~cm} \times 7 \mathrm{~cm}$. Mice were placed in the central area of the maze, facing one of the open arms. The number of arm entries and the time spent in each type of the arm, as well as the time spent in the central area were counted for $5 \mathrm{~min}$ of observation.

\section{Object recognition test}

The procedure was performed according to the method previously described (Ennaceur et al. 1997; Ennaceur and Delacour 1988) and it may be summarized as follows. The apparatus was a gray wooden box $(52.5 \times 37.5 \times 41.5 \mathrm{~cm})$ placed on the floor and lit with the intensity of $40 \mathrm{~lx}$ in a sound isolated room. A day before testing mice were submitted to a habituation session, during which they were allowed to explore the empty apparatus for $5 \mathrm{~min}$. Next day, the experimental session comprised two trials. In the first trial (T1), one object-stimulus, a sample (A), was placed near the rear wall of the box. During the second trial (T2), a new object $(\mathrm{B})$ was added. The object $\left(\mathrm{A}^{\prime}\right)$ presented during T2 was a duplicate of the sample presented in T1 (A) in order to avoid olfactory traits. Both objects, a new and a 
duplicate of the sample presented during $\mathrm{T} 1$, were placed on the opposite back corners. The objects to be discriminated between were made of glass and porcelain, and they differed in shape, color and size, which allowed recognizing them as novelty. Their weights were such that they could not be moved by animals. Positions and roles of objects (sample $v s$ new object) were counterbalanced within each session. Moreover, the object had no natural significance for mice and had never been associated with reinforcement. Different pairs of objects were used for each session. The duration of T1 and T2 was 5 and 3 min, respectively. T2 started 60 min. after T1 began. An exploration was defined as the animal facing the object, with its nose within $2 \mathrm{~cm}$ from the object. Touching the object with nose and turning around was not considered as an exploration. Time spent by mice in objects' exploration during T1 and T2 trials was measured manually using stopwatch. From this measure, the following variables were defined: $A=$ exploration time of the sample presented during $\mathrm{T} 1, \mathrm{~B}=$ exploration time of a new object presented during $\mathrm{T} 2,\left(\mathrm{~B}+\mathrm{A}^{\prime}\right)=$ exploration time of a duplicate $\left(\mathrm{A}^{\prime}\right)$ of the familiar object $\mathrm{A}$ and a new object (B) presented during T2. Object recognition was measured by index of discrimination $\left(B-A^{\prime}\right)$. Since $\left(B-A^{\prime}\right)$ may be biased by differences in overall levels of exploration, the discrimination ratio $(\mathrm{B}-\mathrm{A}) /\left(\mathrm{B}+\mathrm{A}^{\prime}\right)$ was also calculated. The latter one may vary between +1 and -1 . A positive score indicates more time spent with the novel object, a negative score indicates more time spent with the familiar object. A zero score indicates a null preference for objects (Aubele et al. 2008; Ennaceur et al. 1997). Moreover, the recognition index (RI) was calculated for each animal and expressed as a ratio: $(\mathrm{B} \times 100) /\left(\mathrm{B}+\mathrm{A}^{\prime}\right)$. The recognition index around $50 \%$ indicates that animal did not remember the familiar object (since time $\mathrm{A}$ and time $\mathrm{B}$ are comparable), while recognition index above $50 \%$ indicates, that animal has remembered the familiar object, since time B is longer than time A (Balderas et al. 2008; Ennaceur and Delacour 1988).

\section{Statistics}

Statistical analyses were performed using Statistica 13.0 and GraphPad Prism 5. All data were first assessed for normality using the Shapiro-Wilk test. In the present study, some variables measured in object recognition test, and some evaluated in a holeboard test, as well as in elevated plus maze did not have normal distribution. Therefore, data from object recognition test, holeboard and elevated plus maze tests, were analyzed by one-way analysis of variance (ANOVA) with Bonferroni post hoc test or by Kruskal-Wallis followed with Dunn's multiple comparison post hoc test, when appropriate. The effects of genotype and age on parameters measured in the object recognition test, holeboard and the in elevated plus maze were analyzed by General Linear Model (GLM). Differences were considered significant at $p<0.05$. $\mathrm{F}$ values for ANOVA and GLM, as well as $\mathrm{H}$ values for Kruskal-Wallis test, degrees of freedom and $p$ values were given only for significant differences. Due to the lack of interest in a sample presented during $\mathrm{T} 1$ trial of object recognition test one 4-month-old IL-6KO mouse was excluded from statistical analysis, even though it performed well in other behavioral tests, the holeboard and the elevated plus maze.

\section{Results}

\section{Holeboard test}

There were no significant differences between tested groups in total ambulation (Fig. 1a), as well as in peripheral activity (Fig. 1b) and central activity (Fig. 1c) measured by crossings of squares adjacent and squares not adjacent to the apparatus walls, respectively. Out of two parameters used for the evaluation of exploratory activity: rearings (Fig. 1d) and head-dips (Fig. 1e) only rearing events differed between tested groups. ANOVA of rearings yielded $\mathrm{F}(3,35)=7.330$, $p=0.0006$, and Bonferroni post hoc test revealed significant increase in incidences of rearings in 24-month-old WT animals in comparison with 24-month-old IL-6KO ones, $p<0.005$, and to 4-month-old WT mice, $p<0.05$ (Fig. 1d). Moreover, there were no significant differences between tested groups in latency to leave the central area, the parameter reflecting the level of anxiety (Fig. 1f).

Statistical analysis of genotype and age effects on parameters assessed in the holeboard by GLM revealed that peripheral activity and head-dips were age-dependent, rearings were genotype-dependent, while central area latency time was both age- and genotype-dependent (Supplementary Table I). GLM for peripheral activity yielded $\mathrm{F}(1,35)=4.856, p<0.05$, and for head-dips yielded $\mathrm{F}(1,35)=7.588, p<0.01$ indicating significant decrease of both parameters in 24-month-old vs 4-month-old mice. GLM for rearings yielded $\mathrm{F}(1,35)=5.279, p<0.05$ indicating that rearing events were less frequent in IL-6KO mice that in WT mice. Regarding central area latency GLM yielded $\mathrm{F}(1,35)=15.595, p<0.01$ for genotype and $\mathrm{F}(1,35)=8.356$, $p<0.01$ for age showing that IL-6KO mice spent shorter and 24-month-old mice spent longer time in central area of the apparatus. Significant genotype $\mathrm{x}$ age interaction was observed only for rearings $\mathrm{F}(1,35)=15.51, p<0.005$.

\section{Elevated plus maze}

Elevated plus maze test, assessing the level of anxiety, was performed immediately after the holeboard test. No 
A

B

Total ambulation

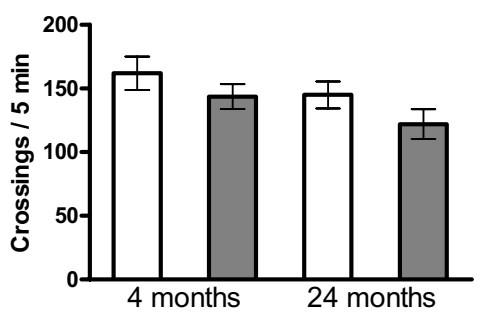

D

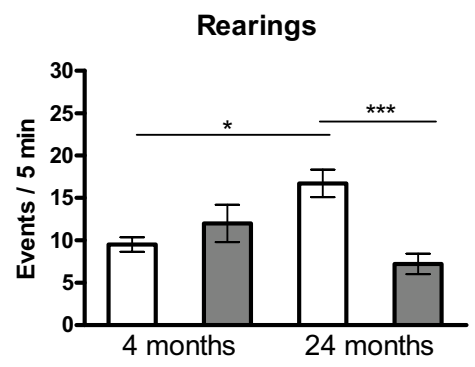

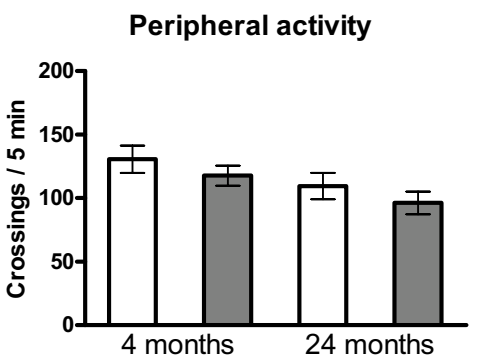

E

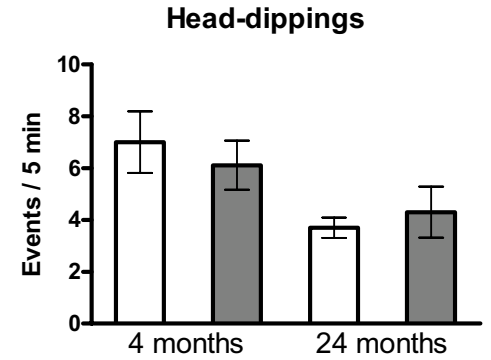

C

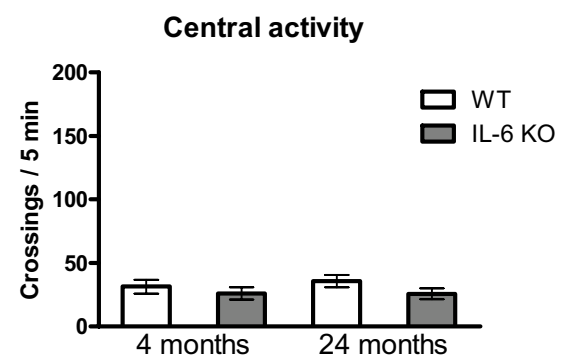

$\mathbf{F}$

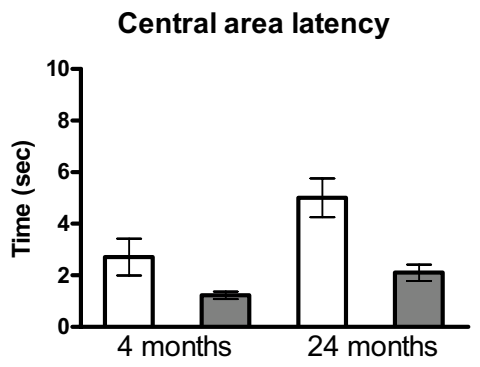

Fig. 1 Effect of IL-6 deficiency on locomotor activity measured by a total, $\mathbf{b}$ peripheral and $\mathbf{c}$ central ambulation, and on exploratory activity measured by $\mathbf{d}$ rearings and $\mathbf{e}$ head-dips in a holeboard test performed on 4- and 24-month-old IL-6KO and age-matched WT mice. f Central area leaving time was used for the evaluation of anxiety level.
Columns represent mean \pm SEM of the values obtained from 9-10 animals. Rearings were less frequent in 24-month-old IL-6KO mice $(* * * p<0.005)$ and in 4-month-old WT ones $(* p<0.05)$ in comparison with 24-month-old WT animals (ANOVA and post hoc Bonferroni test) significant differences were observed between 24-monthold IL-6KO and age-matched WT mice in all tested parameters: closed arm time (Fig. 2a), open arm time (Fig. 2b), and central area time (Fig. 2c), as well as in closed arm entries (Fig. 2d), open arm entries (Fig. 2e), and entry latency (Fig. 2f). Significant differences were observed between 4-month-old IL-6KO and age-matched WT mice only in open arm time (Fig. 2b) and in open arm entries (Fig. 2e). Kruskal-Wallis test yielded H(4,39) $=7.846, p=0.0493$ for open arm time and $\mathrm{H}(4,39)=11.96, p=0.0075$ for open arm entries. Post-hoc comparison with Dunn's test revealed significantly prolonged open arm time $(p<0.05)$ and significantly more entries to open arms $(p<0.01)$ in 4-monthold IL-6KO than in age-matched WT mice (Fig. 2b, e respectively).

When genotype and age effects on parameters assessed in the elevated plus maze were evaluated by GLM, significant increase in open arm time and significant increase in open arm entries were observed in IL-6KO mice in comparison with WT animals (Supplementary Table II). GLM yielded $\mathrm{F}(1,35)=7.244, p<0.05$ for open arm time, and $\mathrm{F}(1,35)=13.812, p<0.01$ for open arm entries. Moreover, aged animals significantly less often visited closed arms in comparison with young adult ones. GLM yielded $F(1,35)=6.414, p<0.05$. Significant genotype $x$ age interaction was observed only for entry latency time $\mathrm{F}(1,35)=4.936, p<0.05$.

\section{Object recognition test}

Time spent by mice on exploration of object A in T1 trial was comparable in four tested groups (Fig. 3). While the exploration time of a duplicate $\left(\mathrm{A}^{\prime}\right)$ of the familiar object and a new object $\mathrm{B}$ during $\mathrm{T} 2$ trial were comparable in 4-monthold IL-6KO and WT mice, the time spent on $\mathrm{A}^{\prime}, \mathrm{B}$ and both objects' $\left(B+A^{\prime}\right)$ exploration in 24-month-old mice were different (Fig. 3). Kruskal-Wallis test yielded H(4,39) =10.79, $p=0.029$ and $\mathrm{H}(4,39)=9.462, p=0.0237$ for the time of objects' $\mathrm{A}^{\prime}$ and $\mathrm{B}+\mathrm{A}^{\prime}$ exploration, respectively, and further post hoc comparison with Dunn's test revealed significantly shorter exploration $(p<0.05)$ of these objects by 24-month-old IL-6KO than age-matched WT mice. ANOVA for the time of object $B$ exploration yielded $F(3,35)=2.814$, $p=0.0354$ and Bonferroni post hoc test showed significantly shorter time of object B exploration by 24-month-old IL$6 \mathrm{KO}$ than WT mice $(p<0.05)$.

Object recognition memory measured by the index of discrimination (difference $B-A^{\prime}$ ) varied between 4-month-old WT mice and other tested groups but the differences were insignificant (Fig. 4a). Analysis of 
A

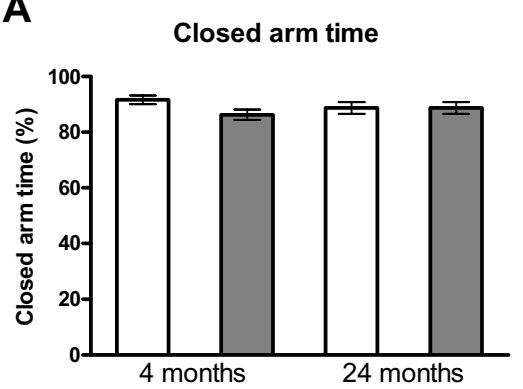

D

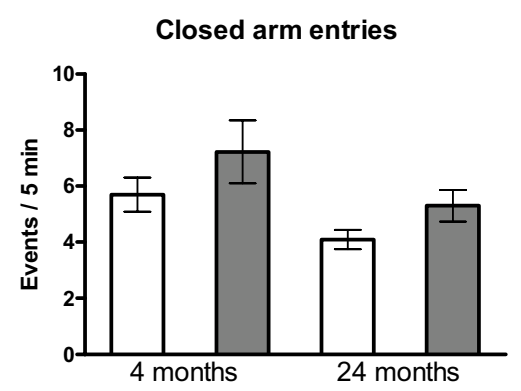

B

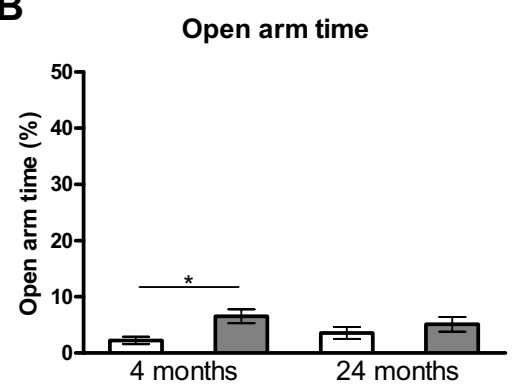

E

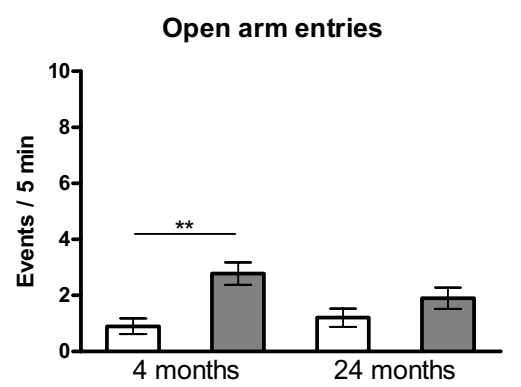

C

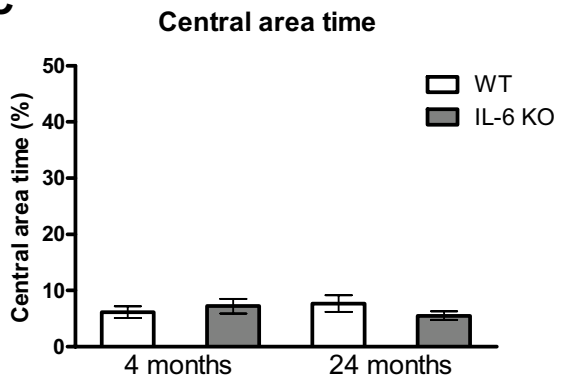

$\mathbf{F}$

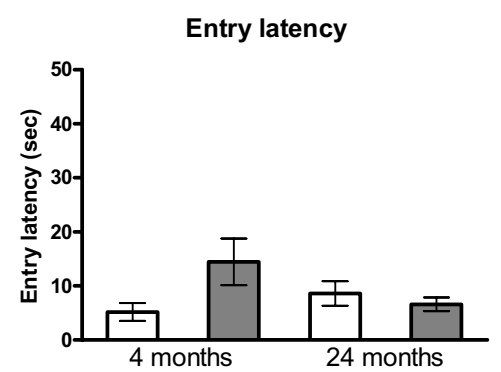

Fig. 2 Effect of IL-6 deficiency on anxiety level evaluated in an elevated plus maze performed on 4- and 24-month-old IL-6KO and age-matched WT mice. Columns represent mean \pm SEM of the values obtained from 9-10 animals. Percent of time spent $\mathbf{a}$ in closed arms, and $\mathbf{c}$ in central area of the apparatus, $\mathbf{f}$ central area latency time and number of entries $\mathbf{d}$ to closed arms were comparable in all tested groups. b 4-month-old IL-6KO mice spent significantly longer time $\left({ }^{*} p<0.05\right)$ and e more frequently visited open arms $(* * p<0.01)$ than 4-month-old WT animals (Kruskal-Wallis test followed by post hoc Dunn's test)

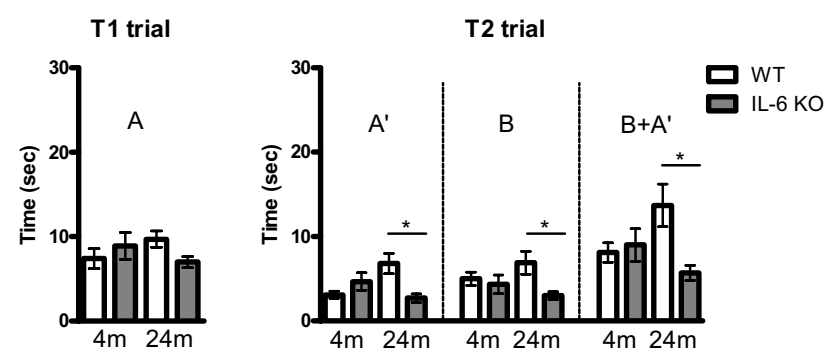

Fig. 3 Effect of IL-6 deficiency on object's exploration during $\mathrm{T} 1$ and $\mathrm{T} 2$ trials in an object recognition test performed on 4- and 24-month-old IL-6KO and age-matched WT mice. Columns represent mean \pm SEM of the values obtained from 9-10 animals. Aexploration time of an object presented during T1 trial, $\mathbf{A}^{\prime}-$ exploration time of a duplicate of familiar object presented during T2 trial, B-exploration time of a novel object presented during T2 trial, $\left(\mathbf{B}+\mathbf{A}^{\prime}\right)$ - the sum of exploration time of both objects presented in T2 trial. 24-month-old IL-6KO mice displayed shorter exploration of object B (ANOVA and post hoc Bonferroni test) and of object $\mathrm{A}^{\prime}$, as well as of both objects $\left(B+A^{\prime}\right)$ evaluated by Kruskal-Wallis test with Dunn's post hoc test $\left({ }^{*} p<0.05\right)$

discrimination ratio $\left(\mathrm{B}-\mathrm{A}^{\prime}\right) /\left(\mathrm{B}+\mathrm{A}^{\prime}\right)$ revealed significant attenuation of object recognition memory in 4-month-old IL-6KO mice and in 24-month-old WT mice in comparison with 4-month-old WT animals. Kruskal-Wallis test yielded $\mathrm{H}(4,39)=10.79, p=0.029$, and further post hoc comparison with Dunn's test revealed the same level of statistical significance for both groups $(p<0.05$, Fig. 4b). Also, recognition index $\left(\mathrm{B} \times 100 / \mathrm{B}+\mathrm{A}^{\prime}\right)$ was different between tested groups (Fig. 4c). While recognition index was over $60 \%$ in young adult WT mice indicating that after 1-hour delay they remembered familiar object, it was below 50\% in 4-month-old IL-6KO and in 24-month-old WT animals indicating that the familiar object was not remembered. Kruskal-Wallis test yielded $\mathrm{H}(4,39)=10.79$, $p=0.029$, and further post hoc comparison with Dunn's test revealed significantly lower recognition index in both 4-month-old IL-6KO mice and in 24-month-old WT mice $(p<0.05)$. In 24 -month-old IL-6KO mice the value of discrimination ratio reached 0.1 and recognition index exceeded 50\% (53.17\%), however they did not show significant differences with any of other tested groups.

GLM evaluation of genotype and age influence on parameters assessed in the object recognition test revealed that only exploration time of object $\mathrm{B}$ and of both objects $\left(\mathrm{B}+\mathrm{A}^{\prime}\right)$ during T2 trial was significantly shorter in IL-6-deficient than WT mice $(p<0.05)$, (Supplementary Table III). GLM for exploration time of object $\mathrm{B}$ yielded $\mathrm{F}(1,35)=5.431$, $p<0.05$, and for exploration time of both objects $\left(\mathrm{B}+\mathrm{A}^{\prime}\right)$ $\mathrm{F}(1,35)=4.138, p<0.05$. Significant genotype $\mathrm{x}$ age 
A

Index of discrimination

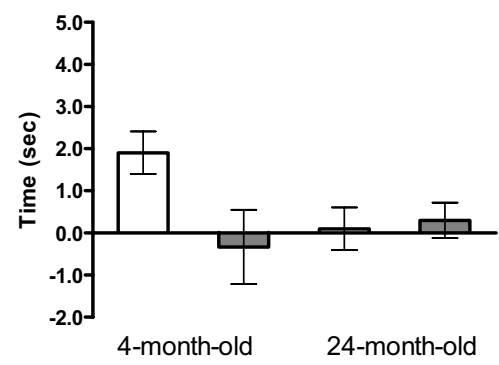

B

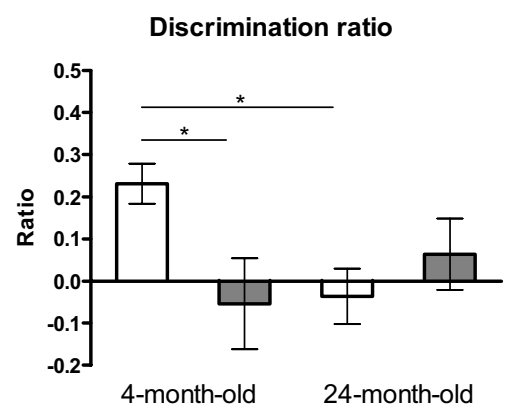

C

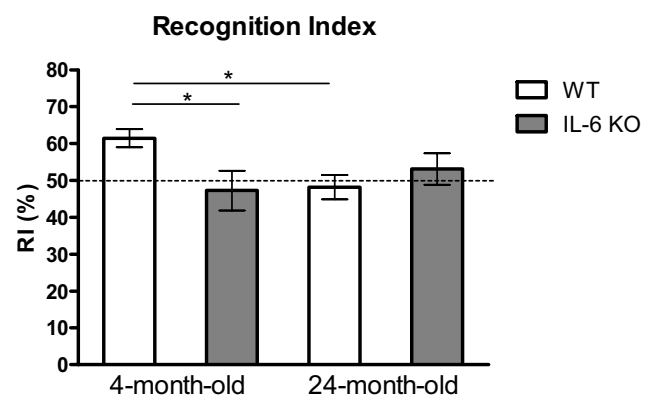

Fig. 4 Effect of IL-6 deficiency on a index of discrimination $\left(\mathrm{B}-\mathrm{A}^{\prime}\right)$, b discrimination ratio $\left(\mathrm{B}-\mathrm{A}^{\prime}\right) /\left(\mathrm{B}+\mathrm{A}^{\prime}\right)$ and $\mathbf{c}$ recognition index $(\mathrm{B} \times 100) /\left(\mathrm{B}+\mathrm{A}^{\prime}\right)$ evaluated in an object recognition test performed on 4- and 24-month-old IL-6KO mice and age-matched WT ones. Columns represent mean \pm SEM of the values obtained from

interactions were observed for all parameters except variables A and B $(p<0.05)$.

\section{Discussion}

Results of the present study supported our previous observation that inborn IL-6 deficiency attenuates recognition memory in young adult mice in comparison with age-matched WT animals (Hryniewicz et al. 2007). The comparison of young adult with aged animals of both genotypes performed in the current study showed attenuation of recognition memory in 24-month-old WT animals as compared to 4-monthold WT ones, and lack of significant differences between 24-month-old IL-6KO mice and other tested groups. After 1-h delay both 4-month-old IL-6KO mice and 24-month-old WT animals did not differentiate a new from the familiar object because their recognition indexes were below $50 \%$ and their discrimination ratios had negative values, and these parameters were significantly lower than in 4-monthold WT animals. Although, in 24-month-old IL-6KO mice recognition index exceeded $50 \%(53.17 \%)$ it was not significantly different in comparison with all other groups. Moreover, while recognition index was significantly attenuated in aged vs young WT mice, in aged IL-6KO animals it was slightly higher than in young adult IL-6KO ones and reached $53.17 \%$, indicating that their recognition memory was not worsened with age. However, it is impossible to exclude from the effect observed in aged IL-6KO mice the involvement of negative influence of inborn IL-6 deficiency on brain development that resulted in the attenuation of recognition memory observed in young adult IL-6KO animals. Although under physiological conditions IL-6 expression in brain tissue is very low, there is an evidence that IL-6 stimulates adult neurogenesis, possesses neurotrophic
9-10 animals. Discrimination ratios and recognition indexes were significantly lower in 4-month-old IL-6KO and in 24-month-old WT mice in comparison with 4-month-old WT animals $\left(^{*} p<0.05\right.$, Kruskal-Wallis test with Dunn's post hoc test)

properties, regulates neuronal survival and function, and modulates neurotransmission in brain structures associated with cognitive processes (Balschun et al. 2004; D'Arcangelo et al. 2000; Erta et al. 2012; Gruol 2015; Islam et al. 2009; Kushima et al. 1992; Kushima and Hatanaka 1992). Moreover, IL-6 was proved to play a role in CNS development. Despite partial redundancy among different IL-6-type family members (Du et al. 1996; Ezure et al. 2000; Spooren et al. 2011) a disturbance of IL-6 signaling in the knock-out mice is likely to affect brain development, and as a consequence, neuronal functions correlated with memory processes, which may explain significant attenuation of recognition memory observed in 4-month-old IL-6KO mice.

Significant attenuation of recognition memory was reported also in 6-month-old IL-6KO mice (Baier et al. 2009), although experiments were performed in animals' home cages and in the first session (T1 trial of our study) two objects were presented. Despite some procedural differences the recognition index in WT and IL-6KO mice (64\% vs 49\%) was similar to that in 12-14-week-old mice in our previous study (64.24\% vs 50\%) and also in 4-month-old mice in the current study (61.46\% vs $48.18 \%)$. While Baier et al. (2009) concluded that observed effect could be partly explained by significantly reduced exploration time in the familiarisation session, in our study the time of object exploration during T1 trial was comparable in all tested groups. Moreover, reported in our study effect was memory-specific because IL-6KO mice performed more entries into the open arms of elevated plus maze and spent there longer time than WT animals. This indicates on their lower anxiety level, and that shorter exploration of the novel object in $\mathrm{T} 2$ trial in object recognition test was not dependent on neophobia. Also, there were no differences between genotypes in the holeboard test except shorter, although not statistically significant, central area latency time in IL-6-deficient mice supporting their 
lower anxiety level. Significantly higher number of rearings in 24-month-old WT than IL-6KO mice may explain significantly longer exploration of both, a duplicate of the familiar object $\mathrm{A}^{\prime}$, and the new object $\mathrm{B}$ in the $\mathrm{T} 2$ trial in the object recognition test.

In a study concerning cognitive processes in aged (24-month-old) IL-6-deficient and WT mice reported by (Dugan et al. 2009) short-term spatial recognition memory was tested by analysing habituation to the spatial distribution of objects in an open field. Aged IL-6- deficient mice showed a greater degree of habituation than age-matched WT animals indicating that they better remembered presented objects. However, in this experimental paradigm, but not in object recognition test used in our study, spatial component of recognition memory, dependent on hippocampus, was important. Therefore, while in our experiment pure visual-perceptual recognition memory was not worsened in aged vs young adult IL-6 KO mice, in Dugan et al. study (2009), performed in experimental paradigm with strong spatial component, IL-6 deficiency even protected against age-related recognition memory decline. Moreover, although in our previous study performed in Morris water maze learning ability (spatial working memory) was attenuated in both young adult and aged IL-6KO mice in comparison with age-matched WT ones (Bialuk et al. 2018), better retrieval process (spatial reference memory) in IL-6-deficient mice was observed (Bialuk et al. 2018; Bialuk and Winnicka 2018). This effect was probably caused by a different delay between learning and testing trial. In the object recognition test it was only $1 \mathrm{~h}$, while in the Morris water maze between completion of 3-day learning and a single probe trial 24-h (Bialuk et al. 2018) or 7-day delay was introduced (Bialuk and Winnicka 2018). Balschun et al. (2004) reported that induced by learning LTP is followed by IL-6 expression detected $8 \mathrm{~h}$ later, which served as negative regulator of LTP, responsible for its termination. Therefore, in the experimental paradigms with long delay between learning and testing trial lack of IL-6 results in longer consolidation process mirrored by the improvement of retrieval process (reference memory). The putative mechanisms underlying different effect of IL-6 deficiency on spatial and recognition memory was described in details in our previous study (Bialuk and Winnicka 2018). Presented above behavioural studies, based on different experimental paradigms in which particular stages of learning and memory are evaluated, indicate that the involvement of IL-6 in cognitive processes is complex and multidirectional.

Accumulating evidence indicates that a crucial role in recognition memory plays perirhinal cortex (Brown and Aggleton 2001; Olarte-Sanchez et al. 2015; Winters et al. 2008; Winters and Bussey 2005), nevertheless, the involvement of hippocampus in some aspects of object recognition task performance was considered in numerous studies
(Aggleton and Brown, 1999; Broadbent et al. 2004; Cassaday and Rawlins 1997; Rossato et al. 2007; Zola et al. 2000). Evidence from animal studies indicates that a system connected with perirhinal cortex is associated with discrimination of the familiarity and recency, whereas the hippocampus is associated with judging the prior occurrence of stimuli constellations. However, it has been also demonstrated that under rigorous testing conditions, an intact hippocampus is not essential for the judgement of the prior occurrence of an object (Winters et al. 2004). Moreover, the findings reported by (Winters and Bussey 2005) supported a role for perirhinal cortex neuronal activity in encoding, consolidation and retrieval of the object recognition memory. In support of this hypothesis, electrophysiological recording studies have provided evidence of neuronal changes related to familiarity of a visual stimulus in the anterior temporal lobe cortex (entorhinal and perirhinal cortices) (Brown et al. 1987; Miller et al. 1991). The involvement of IL-6 in age-related memory disturbances was demonstrated in senescence-accelerated mice (Tha et al. 2000) and in clinical observations on humans. Significant increase of IL-6 expression measured by ELISA in cerebral cortex and in hippocampus was also shown in 24-month-old BALB/c mice in comparison with 1- and 3-month-old animals (Ye and Johnson 1999). However, molecular mechanisms by which IL-6 overexpression lead to cognitive impairment have not been fully elucidated. In postmortem study performed in patients with severe dementia significantly elevated mRNA for IL-6 and TGF- $\beta 1$ levels in the entorhinal cortex as compared with cognitively normal subjects was reported, whereas IL-1 $\beta$ mRNA was very low (Luterman et al. 2000). Massey et al. (Massey et al. 2001) demonstrated that a cholinergic mechanism of synaptic plasticity within perirhinal cortex may play a role in different aspects of perirhinal-mediated object recognition memory processes. It has been shown that choline acetyltransferase activity was significantly lower in IL-6KO than in control mice (Braida et al. 2004), and that elevated level of IL-6 disrupts cholinergic transmission by altering metabotropic glutamate receptor-activated calcium signalling (Nelson et al. 2004). Therefore, both significant decrease of acetylcholine in IL-6KO mice, as well as disruption of cholinergic transmission by increased IL-6 level may be responsible for attenuation of recognition memory observed in IL-6-deficient and in 24-month-old WT animals with age-related elevation of IL-6 concentration, respectively.

Expression of IL-6 increases with age and experiments performed on animals with overexpression of IL-6 showed that not only IL-6 deficiency but also high level of this cytokine affected mechanism of neuroplasticity underlaying memory processes (Bellinger et al. 1995; Nelson et al. 2012; Steffensen et al. 1994), and can interfere with adult neurogenesis thus contributes to the impairment of cognitive functions (Vallieres 
et al. 2002). Epidemiological studies have shown that peripheral IL-6 levels were inversely correlated with cognitive functions in aged subjects (Ershler and Keller 2000; Sarkisian et al. 2008) and chronic peripheral elevation of this cytokine was associated with mild cognitive deficits even in apparently healthy older adults (Bermejo et al. 2008; Marsland et al. 2006). Furthermore, elevated IL-6 level constitutes a significant predictor of transition from mild cognitive impairment to Alzheimer's disease (Bermejo et al. 2008; Ershler and Keller 2000) and progression of this disease in older individuals (Ershler and Keller 2000; Maggio et al. 2006).

Present study supported our previous finding that inborn IL-6 deficiency attenuated recognition memory in young adult mice, and demonstrated significant attenuation of recognition memory in aged WT animals, and that the latter effect was not altered by IL-6 deficiency. However, in experiments performed on aging IL-6KO animals it is impossible to rule out the negative effect of IL-6 deficiency on CNS development. Taking into consideration that inborn IL-6 deficiency impairs CNS development, similar inability of discrimination between a new and the familiar object observed in aged IL-6KO and WT animals reported in the present study does not exclude the possibility, that increasing with age IL-6 expression and especially its overexpression, may impact age-related memory decline. Therefore, IL-6 signalling may constitute a target for development of the protection against memory disturbances connected with IL-6 overexpression.

Acknowledgments The authors wish to thank K. Fiłończuk M.Sc. for excellent assistance with animals.

Funding The study was funded by Medical University of Białystok.

\section{Compliance with ethical standards}

Conflict of interest Izabela Bialuk, Piotr Jakubów, Maria Małgorzata Winnicka declares that they have no conflict of interest.

Ethical approval All applicable international, national, and/or institutional guidelines for the care and use of animals were followed. All performed procedures were in accordance with the ethical standards of the institution at which the study was conducted.

Open Access This article is distributed under the terms of the Creative Commons Attribution 4.0 International License (http://creativeco mmons.org/licenses/by/4.0/), which permits unrestricted use, distribution, and reproduction in any medium, provided you give appropriate credit to the original author(s) and the source, provide a link to the Creative Commons license, and indicate if changes were made.

\section{References}

Aggleton JP, Brown MW (1999) Episodic memory, amnesia, and the hippocampal-anterior thalamic axis. Behav Brain Sci 22:425-444
Aubele T, Kaufman R, Montalmant F, Kritzer MF (2008) Effects of gonadectomy and hormone replacement on a spontaneous novel object recognition task in adult male rats. Horm Behav $54: 244-252$

Baier PC, May U, Scheller J, Rose-John S, Schiffelholz T (2009) Impaired hippocampus-dependent and -independent learning in IL-6 deficient mice. Behav Brain Res 200:192-196

Balderas I, Rodriguez-Ortiz CJ, Salgado-Tonda P, Chavez-Hurtado J, McGaugh JL, Bermudez-Rattoni F (2008) The consolidation of object and context recognition memory involve different regions of the temporal lobe. Learn Mem 15:618-624

Balschun D, Wetzel W, Del RA, Pitossi F, Schneider H, Zuschratter W, Besedovsky HO (2004) Interleukin-6: a cytokine to forget. FASEB J 18:1788-1790

Bellinger FP, Madamba SG, Campbell IL, Siggins GR (1995) Reduced long-term potentiation in the dentate gyrus of transgenic mice with cerebral overexpression of interleukin-6. Neurosci Lett 198:95-98

Bermejo P, Martin-Aragon S, Benedi J, Susin C, Felici E, Gil P, Ribera JM, Villar AM (2008) Differences of peripheral inflammatory markers between mild cognitive impairment and Alzheimer's disease. Immunol Lett 117:198-202

Bialuk I, Winnicka MM (2018) Facilitatory effect of IL-6 deficiency on long-term spatial memory in young adult mice. Behav Genet 48:236-246

Bialuk I, Taranta A, Winnicka MM (2018) IL-6 deficiency alters spatial memory in 4- and 24-month-old mice. Neurobiol Learn Mem 155:21-29

Braida D, Sacerdote P, Panerai AE, Bianchi M, Aloisi AM, Iosue S, Sala M (2004) Cognitive function in young and adult IL (interleukin)-6 deficient mice. Behav Brain Res 153:423-429

Broadbent NJ, Squire LR, Clark RE (2004) Spatial memory, recognition memory, and the hippocampus. Proc Natl Acad Sci USA 101:14515-14520

Brown MW, Aggleton JP (2001) Recognition memory: what are the roles of the perirhinal cortex and hippocampus? Nat Rev Neurosci 2:51-61

Brown MW, Wilson FA, Riches IP (1987) Neuronal evidence that inferomedial temporal cortex is more important than hippocampus in certain processes underlying recognition memory. Brain Res 409:158-162

Cassaday HJ, Rawlins JN (1997) The hippocampus, objects, and their contexts. Behav Neurosci 111:1228-1244

D’Arcangelo G, Tancredi V, Onofri F, D'Antuono M, Giovedi S, Benfenati F (2000) Interleukin-6 inhibits neurotransmitter release and the spread of excitation in the rat cerebral cortex. Eur J Neurosci 12:1241-1252

Du X, Everett ET, Wang G, Lee WH, Yang Z, Williams DA (1996) Murine interleukin-11 (IL-11) is expressed at high levels in the hippocampus and expression is developmentally regulated in the testis. J Cell Physiol 168:362-372

Dugan LL, Ali SS, Shekhtman G, Roberts AJ, Lucero J, Quick KL, Behrens MM (2009) IL-6 mediated degeneration of forebrain GABAergic interneurons and cognitive impairment in aged mice through activation of neuronal NADPH oxidase. PLOS ONE 4:e5518

Ennaceur A, Delacour J (1988) A new one-trial test for neurobiological studies of memory in rats. 1: behavioral data. Behav Brain Res 31:47-59

Ennaceur A, Neave N, Aggleton JP (1997) Spontaneous object recognition and object location memory in rats: the effects of lesions in the cingulate cortices, the medial prefrontal cortex, the cingulum bundle and the fornix. Exp Brain Res 113:509-519

Ershler WB, Keller ET (2000) Age-associated increased interleukin-6 gene expression, late-life diseases, and frailty. Annu Rev Med $51: 245-270$ 
Erta M, Quintana A, Hidalgo J (2012) Interleukin-6, a major cytokine in the central nervous system. Int J Biol Sci 8:1254-1266

Ezure T, Sakamoto T, Tsuji H, Lunz JG III, Murase N, Fung JJ, Demetris AJ (2000) The development and compensation of biliary cirrhosis in interleukin-6-deficient mice. Am J Pathol 156:1627-1639

File SE, Wardill AG (1975) The reliability of the hole-board apparatus. Psychopharmacologia 44:47-51

Godbout JP, Johnson RW (2004) Interleukin-6 in the aging brain. J Neuroimmunol 147:141-144

Gruol DL (2015) IL-6 regulation of synaptic function in the CNS. Neuropharmacology 96:42-54

Hryniewicz A, Bialuk I, Kaminski KA, Winnicka MM (2007) Impairment of recognition memory in interleukin-6 knock-out mice. Eur J Pharmacol 577:219-220

Hunter CA, Jones SA (2015) IL-6 as a keystone cytokine in health and disease. Nat Immunol 16:448-457

Islam O, Gong X, Rose-John S, Heese K (2009) Interleukin-6 and neural stem cells: more than gliogenesis. Mol Biol Cell 20:188-199

Kushima Y, Hatanaka H (1992) Interleukin-6 and leukemia inhibitory factor promote the survival of acetylcholinesterase-positive neurons in culture from embryonic rat spinal cord. Neurosci Lett 143:110-114

Kushima Y, Hama T, Hatanaka H (1992) Interleukin-6 as a neurotrophic factor for promoting the survival of cultured catecholaminergic neurons in a chemically defined medium from fetal and postnatal rat midbrains. Neurosci Res 13:267-280

Luterman JD, Haroutunian V, Yemul S, Ho L, Purohit D, Aisen PS, Mohs R, Pasinetti GM (2000) Cytokine gene expression as a function of the clinical progression of Alzheimer disease dementia. Arch Neurol 57:1153-1160

Maggio M, Guralnik JM, Longo DL, Ferrucci L (2006) Interleukin-6 in aging and chronic disease: a magnificent pathway. J Gerontol A 61:575-584

Marsland AL, Petersen KL, Sathanoori R, Muldoon MF, Neumann SA, Ryan C, Flory JD, Manuck SB (2006) Interleukin-6 covaries inversely with cognitive performance among middle-aged community volunteers. Psychosom Med 68:895-903

Massey PV, Bhabra G, Cho K, Brown MW, Bashir ZI (2001) Activation of muscarinic receptors induces protein synthesis-dependent long-lasting depression in the perirhinal cortex. Eur J Neurosci 14:145-152

McAfoose J, Baune BT (2009) Evidence for a cytokine model of cognitive function. Neurosci Biobehav Rev 33:355-366

Miller EK, Li L, Desimone R (1991) A neural mechanism for working and recognition memory in inferior temporal cortex. Science 254:1377-1379

Mooijaart SP, Sattar N, Trompet S, Lucke J, Stott DJ, Ford I, Jukema JW, Westendorp RG, de Craen AJ (2013) Circulating interleukin-6 concentration and cognitive decline in old age: the PROSPER study. J Intern Med 274:77-85

Nelson TE, Netzeband JG, Gruol DL (2004) Chronic interleukin-6 exposure alters metabotropic glutamate receptor-activated calcium signalling in cerebellar Purkinje neurons. Eur J Neurosci 20:2387-2400

Nelson TE, Olde EA, Hernandez R, Puro A, Huitron-Resendiz S, Hao C, De Graan PN, Gruol DL (2012) Altered synaptic transmission in the hippocampus of transgenic mice with enhanced central nervous systems expression of interleukin-6. Brain Behav Immun 26:959-971

Olarte-Sanchez CM, Amin E, Warburton EC, Aggleton JP (2015) Perirhinal cortex lesions impair tests of object recognition memory but spare novelty detection. Eur J Neurosci 42:3117-3127
Pellow S, Chopin P, File SE, Briley M (1985) Validation of open:closed arm entries in an elevated plus-maze as a measure of anxiety in the rat. J Neurosci Method 14:149-167

Rossato JI, Bevilaqua LR, Myskiw JC, Medina JH, Izquierdo I, Cammarota M (2007) On the role of hippocampal protein synthesis in the consolidation and reconsolidation of object recognition memory. Learn Mem 14:36-46

Sarkisian CA, Gruenewald TL, John BW, Seeman TE (2008) Preliminary evidence for subdimensions of geriatric frailty: the MacArthur study of successful aging. J Am Geriatr Soc 56:2292-2297

Simpson EE, Hodkinson CF, Maylor EA, McCormack JM, Rae G, Strain S, Alexander HD, Wallace JM (2013) Intracellular cytokine production and cognition in healthy older adults. Psychoneuroendocrinology 38:2196-2208

Spooren A, Kolmus K, Laureys G, Clinckers R, De KJ, Haegeman G, Gerlo S (2011) Interleukin-6, a mental cytokine. Brain Res Rev 67:157-183

Steffensen SC, Campbell IL, Henriksen SJ (1994) Site-specific hippocampal pathophysiology due to cerebral overexpression of interleukin-6 in transgenic mice. Brain Res 652:149-153

Tha KK, Okuma Y, Miyazaki H, Murayama T, Uehara T, Hatakeyama R, Hayashi Y, Nomura Y (2000) Changes in expressions of proinflammatory cytokines IL-1beta, TNF-alpha and IL-6 in the brain of senescence accelerated mouse (SAM) P8. Brain Res 885:25-31

Trapero I, Cauli O (2014) Interleukin 6 and cognitive dysfunction. Metab Brain Dis 29:593-608

Vallieres L, Campbell IL, Gage FH, Sawchenko PE (2002) Reduced hippocampal neurogenesis in adult transgenic mice with chronic astrocytic production of interleukin-6. J Neurosci 22:486-492

Weaver JD, Huang MH, Albert M, Harris T, Rowe JW, Seeman TE (2002) Interleukin-6 and risk of cognitive decline: MacArthur studies of successful aging. Neurology 59:371-378

Winters BD, Bussey TJ (2005) Transient inactivation of perirhinal cortex disrupts encoding, retrieval, and consolidation of object recognition memory. J Neurosci 25:52-61

Winters BD, Forwood SE, Cowell RA, Saksida LM, Bussey TJ (2004) Double dissociation between the effects of peri-postrhinal cortex and hippocampal lesions on tests of object recognition and spatial memory: heterogeneity of function within the temporal lobe. J Neurosci 24:5901-5908

Winters BD, Saksida LM, Bussey TJ (2008) Object recognition memory: neurobiological mechanisms of encoding, consolidation and retrieval. Neurosci Biobehav Rev 32:1055-1070

Wright CB, Sacco RL, Rundek T, Delman J, Rabbani L, Elkind M (2006) Interleukin-6 is associated with cognitive function: the Northern Manhattan study. J Stroke Cerebrovasc Dis 15:34-38

Ye SM, Johnson RW (1999) Increased interleukin-6 expression by microglia from brain of aged mice. J Neuroimmunol 93:139-148

Yirmiya R, Goshen I (2011) Immune modulation of learning, memory, neural plasticity and neurogenesis. Brain Behav Immun 25:181-213

Zola P, Maggino T, Sacco M, Rumore A, Sinistrero G, Maggi R, Landoni F, Foglia G, Sartori E, De TJ, Franchi M, Romagnolo C, Sismondi P (2000) Prospective multicenter study on urologic complications after radical surgery with or without radiotherapy in the treatment of stage IB-IIA cervical cancer. Int J Gynecol Cancer 10:59-66

Publisher's Note Springer Nature remains neutral with regard to jurisdictional claims in published maps and institutional affiliations. 